\title{
Pengaruh Employee Engagement Terhadap Kinerja Karyawan Direktorat Sistem Informasi dan Transformasi Digital Institut Pertanian Bogor
}

\section{The Effect of Employee Engagement on Employee Performance of the Directorate of Information Systems and Digital Transformation at Bogor Agricultural University}

Biyanto Daru Wicaksono ${ }^{1 *}$, Siti Rahmawati ${ }^{1}$

1) Departemen Manajemen, Fakultas Ekonomi dan Manajemen, IPB Kampus Dramaga Bogor 16680

\begin{abstract}
Employees who are engaged will give the best performance and do things related to the job optimally in order to achieve the goals of the institution. This study aims to analyze the influence of employee engagement on the performance of employees of the Directorate of Information Systems and Digital Transformation (DSITD) of IPB University. The research method used is quantitative research method, using descriptive statistik analysis and multiple linear regression analysis. The results of the study can be concluded that the state of employee engagement and employee performance in DSITD IPB is in good category. Partially, absorption elements have been found to effect the employee performance. However, together with vigor and dedication, absorption element have an effect of 67,5 percent on employee performance, meaning that of all variables that can affect employee performance, employee engagement only affects 67,5 percent.
\end{abstract}

Keywords: DSITD, employee engagement, IPB University, employee performance.

\begin{abstract}
ABSTRAK
Karyawan yang engaged akan cenderung memberikan kinerja terbaiknya dan melakukan hal-hal yang berhubungan dengan pekerjaan secara maksimal demi mencapai tujuan institusi. Penelitian ini bertujuan menganalisis pengaruh employee engagement terhadap kinerja karyawan Direktorat Sistem Informasi dan Transformasi Digital Institut Pertanian Bogor (DSITD IPB). Metode penelitian yang digunakan adalah metode penelitian kuantitatif, menggunakan analisis statistik deskriptif dan analisis regresi linear berganda. Hasil penelitian dapat disimpulkan bahwa keadaan employee engagement dan kinerja karyawan di DSITD IPB dalam kategori baik. Secara parsial ditemukan pengaruh elemen absorption terhadap kinerja karyawan. Secara bersama vigor, dedication dan absorption memberi pengaruh sebesar $67,5 \%$ terhadap kinerja karyawan, artinya dari keseluruhan variabel yang dapat mempengaruhi kinerja karyawan, employee engagement hanya mempengaruhi sebesar 67,5 persen.
\end{abstract}

Kata kunci: DSITD, employee engagement, IPB, kinerja karyawan.

*Corresponding author

Alamat e-mail: biyanto_daru@apps.ipb.ac.id 


\section{PENDAHULUAN}

Direktorat Sistem Informasi dan Transformasi Digital (DSITD) adalah salah satu Kantor dan Direktorat yang ada di Institut Pertanian Bogor (IPB) yang dulunya bernama Direktorat Integrasi Data dan Sistem Informasi (DIDSI). Direktorat ini diberikan mandat untuk melaksanakan tugas teknis dan administratif institut dalam pengembangan pelayanan sistem informasi serta pengelolaan data berbasis teknologi informasi untuk mendukung penyelenggaraan program institut, termasuk di dalamnya adalah Sistem Informasi Manajemen Kepegawaian (SIMPEG) dan Sistem Informasi Manajemen Kinerja (SIMAKER). Kinerja karyawan DSITD sendiri terbilang baik, sebesar 92,93 persen.

Demi mendukung berjalannya Sistem Informasi Manajemen (SIM) yang ada pada perusahaan atau instansi, maka dibutuhkan Sumber Daya Manusia (SDM) yang memiliki kinerja yang baik. Agar setiap karyawan memiliki kinerja yang baik, maka fungsi pemeliharaan SDM harus berjalan dengan baik pada suatu perusahaan atau instansi tersebut (Sutiyadi, 2017). Perusahaan yang dinamis akan selalu meningkatkan produktivitasnya melalui konsistensi dalam menghasilkan kinerja terbaik serta mempertahankan hal yang menjadi keunggulan kompetitif perusahaan tersebut. Fisher, Schoenfeldt, dan Shaw (2006) mengungkapkan bahwa faktor yang dianggap paling berpotensi dalam penyediaan keunggulan kompetitif perusahaan adalah SDM dan terkait pengelolaannya.

Pengelolaan atau Pemeliharaan (maintenance) SDM harus mendapat prioritas perhatian dari pimpinan. Jika pemeliharaan karyawan kurang diperhatikan maka semangat kerja, sikap dan loyalitas karyawan akan menurun. Hal ini akan berdampak pengadaan, pengembangan, kompensasi, dan pengintegrasian yang telah dilakukan dengan baik dan biaya yang besar kurang berarti untuk menunjang tercapainya tujuan perusahaan (Suwatno \& Priansa, 2011). Data Sasaran Kinerja Pegawai (SKP), presensi dan kehadiran tepat waktu karyawan DSITD dari tahun 2014 2017 dapat dilihat pada Gambar 1.

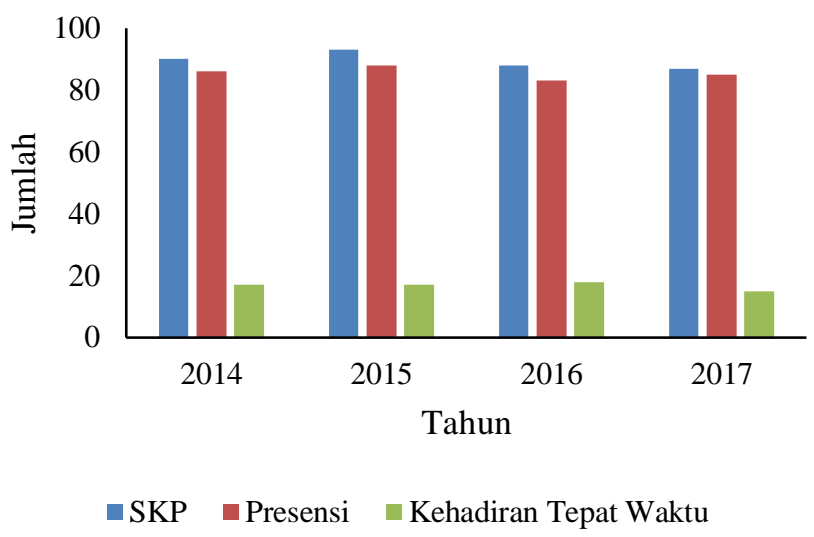

Gambar 1. Hasil SKP, Presensi dan Kehadiran Tepat Waktu DSITD 2014-2017

Jika melihat kecenderungan data di atas, maka tampak adanya permasalahan, yaitu kinerja karyawan tinggi dengan tingkat presensi kehadiran yang baik namun tingkat ketepatan waktu ketika masuk kerja para karyawan kurang. Hal ini diduga terindikasi oleh pemeliharaan SDM yang kurang baik. Salah satu bentuk pemeliharaan agar setiap karyawan memiliki kinerja yang baik adalah dengan memotivasi dan membuat mereka merasa terikat dengan perusahaan, baik pada nilai-nilai yang dianut atau pada lingkungan dan proses kerja yang ada pada perusahaan atau instansi tersebut.

Keterikatan karyawan (employee engagement) sendiri merupakan sebuah konsep yang diyakini dapat meningkatkan kinerja karyawan, karena employee engagement itu sendiri adalah keadaan dimana anggota dari sebuah organisasi melaksanakan peran kerjanya, bekerja dan mengekspresikan dirinya secara fisik (energi yang dikeluarkan karyawan ketika melaksanakan pekerjaannya), kognitif (keinginan yang dimiliki karyawan mengenai organisasi, pemimpin dan kondisi kerja dalam organisasi) dan emosional (meliputi perasaan karyawan terhadap organisasi

Jurnal Manajemen dan Organisasi JMO), Vol. 10 No. 2 , Agustus 2019 
dan pemimpinnya) selama menunjukan kinerja mereka (Kahn, 1990). Employee engagement merupakan konstruk yang menyentuh hampir seluruh permasalahan dalam manajemen sumberdaya manusia. Konstruk ini merupakan variabel yang memiliki pengaruh prediksi akan hubungan dua arah antara karyawan dengan perusahaan dalam hal pengukuran kinerjanya, jika dibandingkan dengan kontruk sebelumnya, yaitu: kepuasan kerja (job satisfaction), komitmen karyawan (employee commitment), dan organizational citizenship (Markos \& Sridevi, 2010).

Pengaruh employee engagement terhadap kinerja karyawan sangat penting, karena rasa keterikatan (engaged) yang dibangun karyawan dengan perusahaan tempatnya bekerja merupakan hal yang penting. Sense of belonging keduanya juga dapat memberikan feedback pada manajemen dan loyalitas pada perusahaan. Keterikatan yang sengaja dibangun ini senantiasa menciptakan kekritisan yang positif pada karyawannya (Surur, 2018). Berdasarkan penjelasan di atas, maka penulis tertarik untuk meneliti kembali fenomena tersebut, yaitu pengaruh employee engagement terhadap kinerja karyawan DSITD Institut Pertanian Bogor.

\section{METODE PENELITIAN}

Penelitian ini mengambil obyek penelitian yang difokuskan pada karyawan DSITD IPB dengan elemen-elemen dari employee engagement (Shcaufeli \& Bakker, 2004) dan aspek kinerja karyawan (BKN, 2011). Elemen-elemen employee engagement yang digunakan adalah vigor, dedication, dan absorption. Sementara aspek kinerja karyawan yang digunakan adalah kuantitas, kualitas, dan waktu. Peneliti menganalisis masing-masing elemen employee engagement terhadap kinerja karyawan dengan regresi linear berganda, kemudian menyimpulkan implikasi manajerial elemen yang berpengaruh pada kinerja karyawan di DSITD IPB setelah diperoleh hasil dari analisis yang sudah dilakukan di penelitian ini. Kerangka penelitian ini dapat dilihat pada Gambar 2.

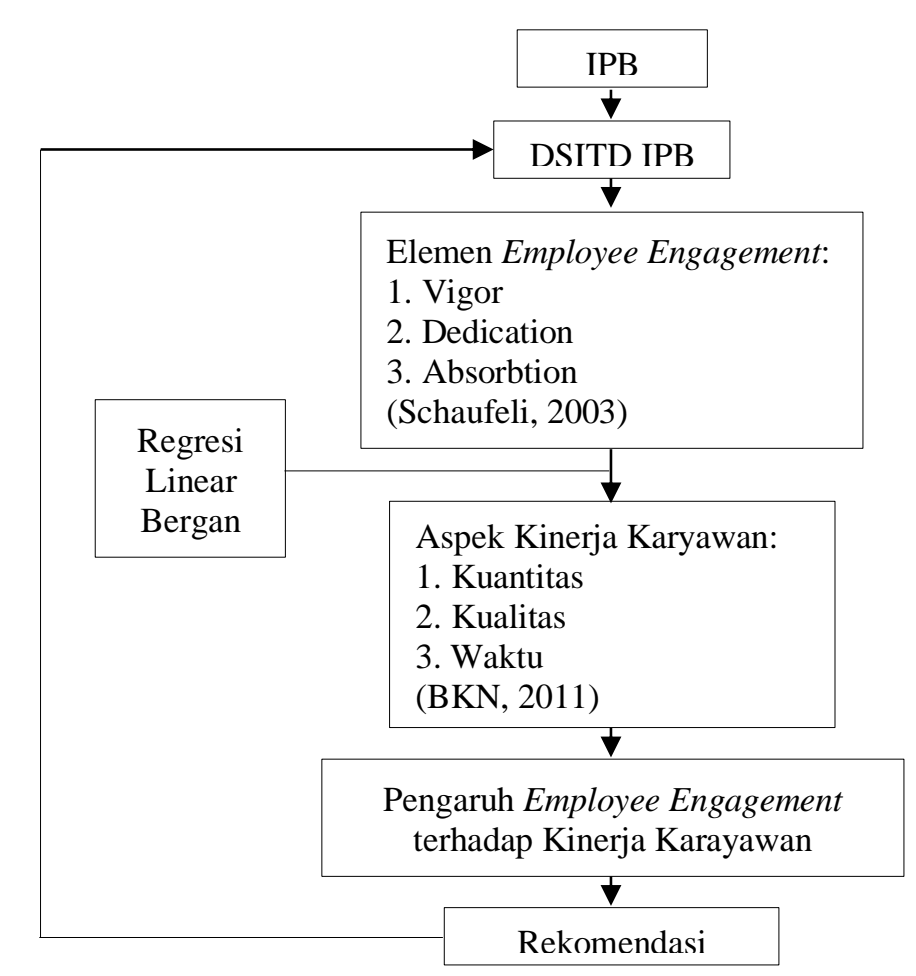

Gambar 2. Kerangka pemikiran penelitian

Penelitian ini dilakukan di Kantor Direktorat Sistem Informasi dan Transformasi Digital Institut Pertanian Bogor, yang berlokasi di Gedung Perpustakaan Baru Lantai 3 Kampus Dramaga IPB, Jawa Barat. Kedua jenis data yang digunakan, yaitu data primer dan sekunder dianalisis dalam penelitian ini. Data primer yang digunakan adalah data kuesioner langsung yang disebarkan kepada seluruh karyawan DSITD IPB. Data sekunder yang digunakan adalah data SKP, data 
presensi dan data kehadiran tepat waktu dari karyawan DSITD IPB per empat tahun terakhir sebagai bukti dari indikasi terhadap bagaimana employee engagement dan kinerja karyawan dari DSITD IPB. Data lainnya didapat dari penelusuran melalui kepustakaan, buku, jurnal, skripsi dan internet. Penelitian ini menggunakan teknik purposive sampling dalam menentukan sampel yang digunakan. Sampel yang diambil adalah seluruh karyawan DSITD IPB yang masih aktif dan sudah bekerja selama satu tahun atau lebih, dan bukan staf teknis, administrasi atau pejabat struktural. Jumlah sampel keseluruhan dalam penelitian ini adalah 33 orang. Teknik pengumpulan data yang digunakan adalah penyebaran kuesioner. Kuesioner dibuat dengan menggunakan skala Likert. Penelitian ini menggunakan uji validitas dan reliabilitas data, analisis statistik deskriptif, uji asumsi klasik, analisis regresi linear dan uji hipotesis (Uji F \& Uji T) terhadap data primer yang didapat dari penyebaran kuesioner. Pengolahan data dibantu dengan software Microsoft Excel dan software IBM SPSS Statistiks 23.

\section{HASIL DAN PEMBAHASAN}

\section{Gambaran Umum Perusahaan}

Institut Pertanian Bogor (IPB) memiliki sejarah yang relatif panjang. Berawal dari Universitas Indonesia di Bogor yang menjadi cikal bakal pendidikan tinggi pertanian pertama di tanah air pada tahun 1940. Selanjutnya, berdasarkan Surat Keputusan Menteri Perguruan Tinggi dan Ilmu Pengetahuan No. 91 Tahun 1963 dan disahkan oleh Keputusan Presiden Republik Indonesia No. 279 Tahun 1965 pada tanggal 1 September 1963 memisahkan diri dari induknya yang berpusat di Jakarta menjadi Institut Pertanian di Bogor.

Pengembangan dan penerapan Teknologi dan Sistem Informasi yang progresif dan adaptif mutlak diperlukan di IPB baik dalam mencapai tujuan organisasi. Awalnya unit kerja yang dibentuk adalah Unit Pelaksana Teknis (UPT) Pusat Komputer. Dalam perkembangan institusi, UPT Puskom berganti nama menjadi Kantor Pengembangan Sistem Informasi (KPSI) sekitar tahun 2001. Perubahan nama dari Kantor Pengembangan Sistem Informasi (KPSI) menjadi Direktorat Komunikasi dan Sistem Informasi (DKSI) melalui Ketetapan MWA No.77/MWAIPB/2008 dan SK Rektor No. 023/I3/OT/2008. Dengan menjadi sebuah direktorat, maka lingkup pekerjaan unit kerja ini menjadi lebih luas. Lalu pada tahun 2008, Kantor Pengembangan Sistem Informasi berubah menjadi Direktorat Komunikasi dan Sistem Informasi (DKSI). Perubahan nama dari Kantor Pengembangan Sistem Informasi (KPSI) menjadi Direktorat Komunikasi dan Sistem Informasi (DKSI) dengan tupoksi yang ditetapkan pada SK Rektor No. 170/I3/OT/2008 tentang Tugas Pokok dan Fungsi Direktorat, Kantor dan Sekretarias Eksekutif IPB. Pada pertengahan 04 Juli 2013 Direktorat Komunikasi dan Sistem Informasi berubah menjadi Direktorat Integrasi Data dan Sistem Informasi (DIDSI). Dan pada 29 Desember 2017 dengan mengacu pada SK rektor nomor 38/IT3.MWA/OT/2020 mengalami perubahan nama menjadi Direktorat Sistem Informasi dan Transformasi Digital (DSITD).

\section{Employee Engagement di DSITD IPB}

Hasil Uji Validitas dan Reliabilitas Elemen Employee Engagement

Hasil uji validitas elemen employee engagement yang dilakukan kepada seluruh karyawan dapat dilihat pada Tabel 1. 
Tabel 1. Hasil Uji Validitas Elemen Employee Engagement

\begin{tabular}{lcc}
\hline Variabel & Corrected Item-Total Correlation & Keterangan \\
\hline Vigor1 & 0,735 & Valid \\
Vigor2 & 0,604 & Valid \\
Vigor3 & 0,482 & Valid \\
Vigor4 & 0,364 & Valid \\
Vigor5 & 0,420 & Valid \\
Dedication1 & 0,417 & Valid \\
Dedication2 & 0,675 & Valid \\
Dedication3 & 0,735 & Valid \\
Dedication4 & 0,699 & Valid \\
Dedication5 & 0,416 & Valid \\
Absorption1 & 0,444 & Valid \\
Absorption2 & 0,492 & Valid \\
Absorption3 & 0,793 & Valid \\
Absorption4 & 0,716 & Valid \\
Absorption5 & 0,621 & Valid \\
\hline Sumbor: Data diah
\end{tabular}

Sumber: Data diolah (2018)

Hasil uji validitas pada Tabel 1 yang dilakukan terhadap butir-butir dari elemen variabel kinerja karyawan menyatakan semua elemen yang diuji valid. Dari tabel diatas dapat dijelaskan bahwa nilai $r$ hitung $>r$ tabel berdasarkan uji signifikan 0,05 , artinya bahwa item-item tersebut di atas valid.

Tabel 2. Hasil Uji Reliabilitas Elemen Employee Engagement

\begin{tabular}{ccc} 
Cronbach's Alpha & Cronbach's Alpha Based on Standardized Items & Keterangan \\
\hline 0,753 & 0,948 & Reliabel
\end{tabular}

Sumber: Data diolah (2018)

Hasil uji reliabilitas pada Tabel 2 menunjukkan bahwa semua variabel reliabel, terlihat dari Nilai Cronbach Alpha sebesar 0,753.

Analisis Deskriptif Elemen Employee Engagement

Employee engagement terdiri dari tiga elemen yaitu vigor, dedication, dan absorption. Elemen-elemen tersebut dianalisis berdasarkan persepsi karyawan tentang employee engagement. Hasil analisis deskriptif dapat dilihat pada Tabel 3 berikut.

Tabel 3. Hasil Analisis Deskriptif Employee Engagement

\begin{tabular}{ccc}
\hline Indikator & Total Skor Rataan & Interpretasi \\
\hline Vigor & 3,624 & Baik \\
Dedication & 3,964 & Baik \\
Absorption & 3,897 & Baik \\
Rataan & 3,828 & \\
Indikator & & \\
\hline
\end{tabular}

Sumber: Data diolah (2018)

Tabel 3 di atas menunjukkan total skor rataan keseluruhan indikator employee engagement bernilai 3,828. Berdasarkan kriteria interval hasil dari analisis statistik deskriptif, nilai 3,828 masuk dalam kategori baik, yang berarti secara umum karyawan DSITD IPB memiliki persepsi yang baik terhadap employee engagement. Elemen dedication memiliki skor tertinggi jika dibandingkan dengan hasil analisis dari elemen lain yaitu sebesar 3,964, elemen ini masuk dalam kategori baik. Hal ini ditunjukkan dengan karyawan muda yang masih antusias dengan tantangan dalam pekerjaan dan perubahan-perubahan dalam spesifikasi pekerjaan yang cepat, sehingga mereka merasa tertantang atas pekerjaan mereka, menghasilkan hasil pekerjaan yang sangat memuaskan, bermakna, penuh arti dan menjadi kebanggaan tersendiri bagi karyawan yang terlibat di dalamnya. Nilai kedua terbesar adalah total skor rataan indikator Absorption sebesar 3,897. Interpretasi dari hasil analisis tersebut adalah karyawan DSITD IPB secara umum memberikan perhatian penuh terhadap tugas-tugas yang diberikan. Untuk hasil analisis nilai total skor rataan 
dari elemen vigor sebesar 3,624 yang mendapatkan nilai paling kecil di antara indikator employee engagement yang lain dapat diinterpretasikan sebagai perilaku karyawan yang secara umum merasa kuat secara fisik dan mental dalam menghadapi pekerjaan juga gigih dalam menghadapi kesulitan pekerjaan.

Persepsi Karyawan DSITD terhadap Vigor

Vigor merupakan salah satu elemen dari employee engagement. Persepsi karyawan tentang elemen vigor dapat dilihat pada Tabel 4.

Tabel 4. Persepsi Karyawan DSITD tentang Vigor.

\begin{tabular}{|c|c|c|c|c|c|c|c|}
\hline \multirow{2}{*}{ Pernyataan } & \multicolumn{5}{|c|}{ Jawaban Karyawan } & \multirow[b]{2}{*}{ Modus } & \multirow[b]{2}{*}{ Keterangan } \\
\hline & $\begin{array}{c}1 \\
\text { STS } \\
(\%)\end{array}$ & $\begin{array}{c}2 \\
\mathrm{TS} \\
(\%)\end{array}$ & $\begin{array}{c}3 \\
\mathrm{KS} \\
(\%)\end{array}$ & $\begin{array}{c}4 \\
\mathrm{~S} \\
(\%)\end{array}$ & $\begin{array}{c}5 \\
\mathrm{SS} \\
(\%)\end{array}$ & & \\
\hline $\begin{array}{l}\text { Ketika bangun di pagi hari, merasa } \\
\text { ingin pergi kerja }\end{array}$ & 0 & 6,1 & 12,1 & 63,6 & 18,2 & 63,6 & Setuju \\
\hline $\begin{array}{l}\text { Bersungguh-sungguh dalam } \\
\text { mengerjakan pekerjaan }\end{array}$ & 0 & 3,0 & 15,2 & 51,5 & 30,3 & 51,5 & Setuju \\
\hline $\begin{array}{l}\text { Pantang menyerah dalam bekerja, } \\
\text { walaupun menghadapi kesulitan }\end{array}$ & 0 & 6,1 & 33,3 & 45,5 & 15,2 & 45,5 & Setuju \\
\hline $\begin{array}{l}\text { Merasakan kebugaran jasmani pada } \\
\text { diri ketika bekerja }\end{array}$ & 39,4 & 21,2 & 24,2 & 15,2 & 0 & 39,4 & $\begin{array}{l}\text { Sangat Tidak } \\
\text { Setuju }\end{array}$ \\
\hline $\begin{array}{l}\text { Dapat terus bekerja untuk waktu yang } \\
\text { sangat lama }\end{array}$ & 0 & 0 & 18,2 & 39,4 & 42,4 & 42,4 & Sangat Setuju \\
\hline
\end{tabular}

Sumber: Data diolah (2018)

*Keterangan: STS = Sangat Tidak Setuju, TS = Tidak Setuju, KS = Kurang Setuju, S = Setuju, SS = Sangat Setuju

Tabel 4 menunjukkan modus jawaban karyawan pada setiap pernyataan. Pernyataan tersebut antara lain ketika karyawan bangun di pagi hari, karyawan merasa ingin pergi kerja, bersungguh-sungguh dalam mengerjakan pekerjaan dan pantang menyerah dalam bekerja, walaupun menghadapi kesulitan. Karyawan sangat tidak setuju dengan pernyataan bahwa karyawan merasakan kebugaran jasmani pada dirinya ketika bekerja namun karyawan sangat setuju dengan pernyataan bahwa karyawan dapat terus bekerja dalam waktu yang sangat lama. Hal ini terjadi karena jenis pekerjaan yang ada pada DSITD IPB tidak memerlukan banyak gerakan fisik, pekerjaan dapat dikerjakan dalam posisi duduk, terkadang dalam waktu yang sangat lama. Tipe pekerjaan yang ada di DSITD juga tidak terikat dengan jam kerja, karena pekerjaan bisa dikerjakan di luar kantor dan di luar jam kerja.

Persepsi Karyawan DSITD terhadap Dedication

Dedication merupakan salah satu elemen dari employee engagement. Persepsi karyawan tentang elemen dedication dapat dilihat pada Tabel 5.

Tabel 5. Persepsi Karyawan DSITD tentang Dedication

\begin{tabular}{|c|c|c|c|c|c|c|c|}
\hline \multirow[b]{2}{*}{ Pernyataan } & \multicolumn{5}{|c|}{ Jawaban Karyawan } & \multirow[b]{2}{*}{ Modus } & \multirow[b]{2}{*}{ Keterangan } \\
\hline & $\begin{array}{c}1 \\
\text { STS } \\
(\%)\end{array}$ & $\begin{array}{c}2 \\
\text { TS } \\
(\%)\end{array}$ & $\begin{array}{c}3 \\
\mathrm{KS} \\
(\%)\end{array}$ & $\begin{array}{c}4 \\
\mathrm{~S} \\
(\%)\end{array}$ & $\begin{array}{c}5 \\
\text { SS } \\
(\%)\end{array}$ & & \\
\hline Pekerjaan sangat bermakna & 0 & 0 & 15,2 & 57,6 & 27,3 & 57,6 & Setuju \\
\hline Antusias dengan pekerjaan & 3,0 & 0 & 27,3 & 51,5 & 18,2 & 51,5 & Setuju \\
\hline Terinspirasi oleh pekerjaan & 0 & 6,1 & 12,1 & 63,6 & 18,2 & 63,6 & Setuju \\
\hline Pekerjaan sangat menantang & 0 & 0 & 15,2 & 69,7 & 15,2 & 69,7 & Setuju \\
\hline Merasa bangga dengan pekerjaan & 0 & 6,1 & 12,1 & 63,6 & 18,2 & 63,6 & Setuju \\
\hline
\end{tabular}

Sumber: Data diolah (2018)

*Keterangan: STS = Sangat Tidak Setuju, TS = Tidak Setuju, KS = Kurang Setuju, $\mathrm{S}=$ Setuju, SS = Sangat Setuju 
Tabel 5 menunjukkan modus jawaban karyawan pada setiap pernyataan. Karyawan setuju bahwa pekerjaan mereka sangat bermakna, karyawan juga merasa antusias dan bangga terhadap pekerjaannya, karyawan juga merasa terinspirasi dan tertantang oleh pekerjaannya.

Persepsi Karyawan DSITD terhadap Absorption

Absorption merupakan salah satu elemen dari employee engagement. Persepsi karyawan tentang elemen absorption dapat dilihat pada Tabel 6.

Tabel 6. Persepsi Karyawan DSITD tentang Absorption

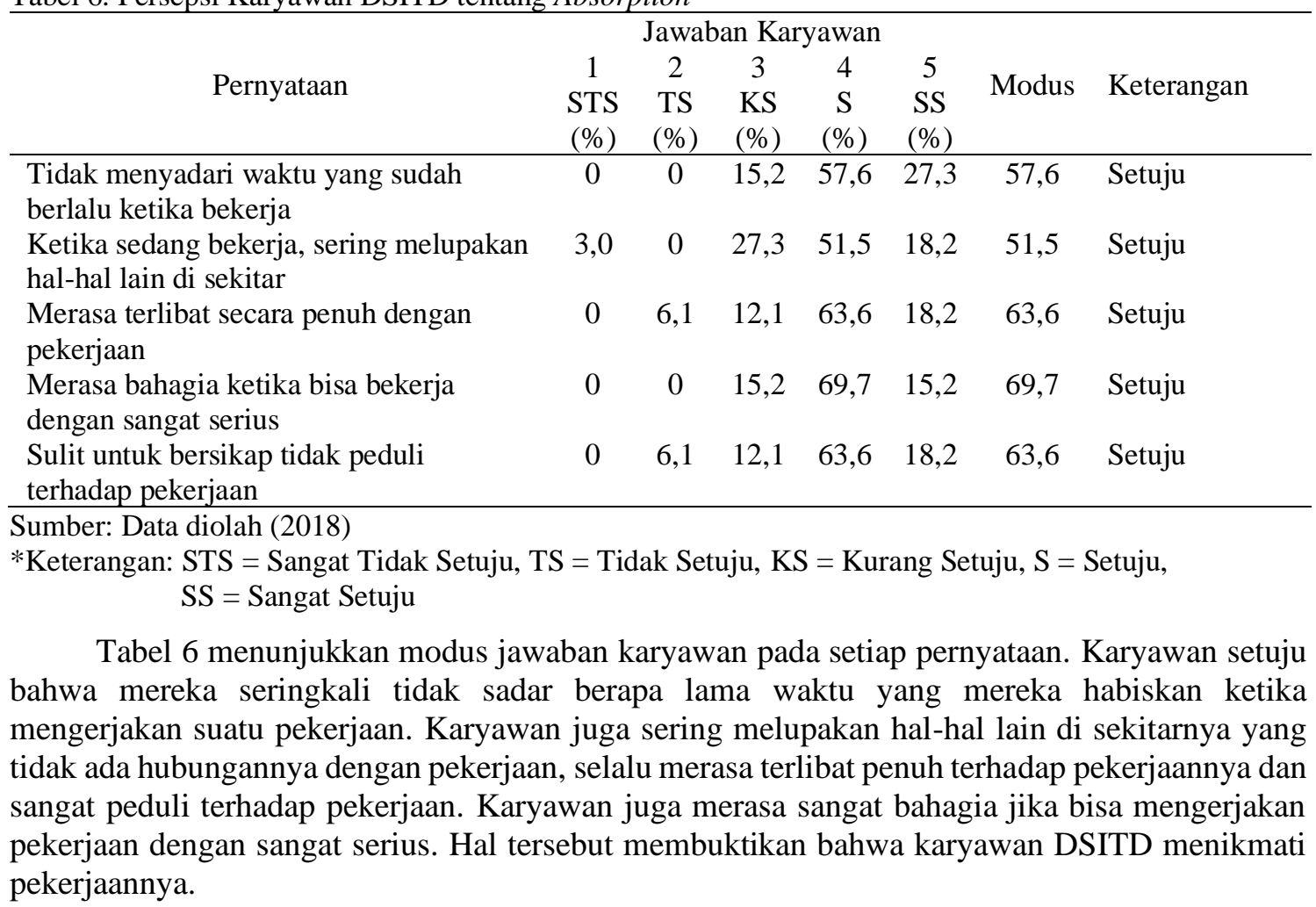

\section{Kinerja Karyawan di DSITD IPB}

Hasil Uji Validitas dan Reliabilitas Aspek Kinerja Karyawan

Hasil uji validitas elemen employee engagement dan aspek kinerja karyawan yang dilakukan kepada seluruh karyawan dapat dilihat pada Tabel 7.

Tabel 7. Hasil Uji Validitas Aspek Kinerja Karyawan

\begin{tabular}{ccc}
\hline Variabel & Corrected Item-Total Correlation & Keterangan \\
\hline Kuantitas1 & 0,811 & Valid \\
Kuantitas2 & 0,853 & Valid \\
Kualitas1 & 0,680 & Valid \\
Kualitas2 & 0,481 & Valid \\
Kualitas3 & 0,697 & Valid \\
Kualitas4 & 0,609 & Valid \\
Kualitas5 & 0,385 & Valid \\
Waktu1 & 0,709 & Valid \\
Waktu2 & 0,742 & Valid \\
Waktu3 & 0,709 & Valid \\
Waktu4 & 0,800 & Valid \\
\hline Sumber: Data diolah (2018) &
\end{tabular}


Hasil uji validitas pada Tabel 7 yang dilakukan terhadap butir-butir dari indikator aspek kinerja karyawan menyatakan semua aspek yang diuji valid karena masing-masing nilai dari Corrected Time-Total Correlation variabel kinerja karyawan lebih besar dari nilai $r$ tabel yang bernilai 0,344 .

Tabel 8. Hasil Uji Reliabilitas

\begin{tabular}{ccc}
\hline Cronbach's Alpha & $\begin{array}{c}\text { Cronbach's Alpha Based on } \\
\text { Standardized Items }\end{array}$ & Keterangan \\
\hline 0,753 & 0,948 & Reliabel \\
\hline
\end{tabular}

Sumber: Data diolah (2018)

Hasil uji reliabilitas pada Tabel 8 menunjukkan bahwa semua variabel reliabel karena memiliki nilai Cronbach's Alpha lebih besar dari 0,60.

Analisis Statistik Deskriptif Aspek Kinerja Karyawan

Kinerja karyawan terdiri dari tiga aspek yaitu kuantitas, kualitas, dan waktu. Aspek-aspek tersebut dianalisis berdasarkan persepsi karyawan tentang kinerja karyawan. Hasil analisis deskriptif ini berupa persepsi karyawan tentang kinerja karyawan.

Tabel 9. Hasil Analisis Deskriptif Kinerja Karyawan

\begin{tabular}{ccc}
\hline Aspek & Total Skor Rataan & Interpretasi \\
\hline Kuantitas & 3,818 & Baik \\
Kualitas & 3,758 & Baik \\
Waktu & 3,689 & Baik \\
\hline
\end{tabular}

Sumber: Data diolah (2018)

Tabel 9 menunjukkan total skor rataan aspek kinerja karyawan adalah 3,755. Berdasarkan kriteria interval hasil dari analisis statistik deskriptif maka nilai 3,755 masuk dalam kategori baik. Aspek kuantitas memiliki skor tertinggi jika dibandingkan dengan aspek lain yaitu sebesar 3,818. Karyawan DSITD IPB secara umum selalu berusaha untuk bekerja sesuai dengan sasaran yang telah ditentukan dan memenuhinya. Nilai terbesar kedua adalah nilai total skor rataan dari aspek kualitas, nilai rataan yang didapat aspek kualitas adalah 3,758 dan masuk dalam kategori baik. Secara umum karyawan DSITD IPB selalu mengerjakan pekerjaan dengan mengikuti deskripsi pekerjaan, menyelesaikannya sesuai ketentuan-ketentuan dan permintaan dari user. Jika dalam pengerjaan didapati ada kesalahan maka karyawan DSITD IPB bersedia mengerjakan ulang pekerjaan tersebut, meningkatkan kompetensi dan kemampuan teknis agar tidak terjadi kesalahan yang sama. Aspek terakhir adalah waktu. Aspek waktu memperoleh nilai 3,689 dan masih masuk dalam kategori baik. Secara umum karyawan DSITD IPB selalu berusaha datang di jam kerja tepat waktu meskipun tingkat ketepatan waktu masuk kerja antara PNS masih lebih baik dari karyawan kontrak. Hal ini dikarenakan adanya rasa keterikatan terhadap status kepegawaian. Karyawan DSITD IPB tidak selalu menyelesaikan pekerjaan sesuai deadline, hal tersebut terjadi karena permintaan user pada deskripsi pekerjaan sering bertambah dan/atau berubah secara cepat dan tidak terduga. Konsekuensi terhadap hal tersebut karyawan DSITD IPB siap untuk pulang lebih akhir demi menyelesaikan pekerjaan yang belum terselesaikan atau mendesak untuk segera diselesaikan.

Persepsi Karyawan DSITD IPB Terhadap Aspek Kuantitas

Kuantitas merupakan salah satu aspek dari kinerja karyawan. Persepsi karyawan tentang aspek kuantitas dapat dilihat pada Tabel 10. 
Tabel 10. Persepsi Karyawan DSITD IPB tentang Aspek Kuantitas

\begin{tabular}{lccccccl}
\hline & \multicolumn{4}{c}{ Jawaban Karyawan } & & Modus & Keterangan \\
& 1 & 2 & 3 & 4 & 5 & & \\
& STS & TS & KS & S & SS & & \\
& $(\%)$ & $(\%)$ & $(\%)$ & $(\%)$ & $(\%)$ & & \\
\hline $\begin{array}{l}\text { Bekerja melampaui sasaran } \\
\text { yang telah ditentukan }\end{array}$ & 0 & 15,2 & 12,1 & 57,6 & 15,2 & 57,6 & Setuju \\
$\begin{array}{l}\text { Mengerjakan pekerjaan sesuai } \\
\text { dengan deskripsi pekerjaan }\end{array}$ & 0 & 3 & 21,2 & 57,6 & 18,2 & 57,6 & Setuju \\
\hline
\end{tabular}

Sumber: Data diolah (2018)

*Keterangan: STS = Sangat Tidak Setuju, TS = Tidak Setuju, KS = Kurang Setuju, S = Setuju, SS $=$ Sangat Setuju

Tabel 10 menunjukkan modus jawaban karyawan pada setiap pernyataan. Karyawan setuju bahwa mereka merasa sudah bekerja melampaui sasaran yang telah ditentukan dan mengerjakan pekerjaan sesuai dengan deskripsi yang diberikan.

Persepsi Karyawan DSITD IPB Terhadap Aspek Kualitas

Kualitas merupakan salah satu aspek dari kinerja karyawan. Persepsi karyawan terhadap aspek kualitas dapat dilihat pada Tabel 11.

Tabel 11. Persepsi Karyawan DSITD IPB tentang Aspek Kualitas

\begin{tabular}{|c|c|c|c|c|c|c|c|}
\hline \multirow{2}{*}{ Pernyataan } & \multicolumn{5}{|c|}{ Jawaban Karyawan } & \multirow[b]{2}{*}{ Modus } & \multirow[b]{2}{*}{ Keterangan } \\
\hline & $\begin{array}{c}1 \\
\text { STS } \\
(\%)\end{array}$ & $\begin{array}{c}2 \\
\text { TS } \\
(\%)\end{array}$ & $\begin{array}{c}3 \\
\mathrm{KS} \\
(\%)\end{array}$ & $\begin{array}{c}4 \\
\mathrm{~S} \\
(\%)\end{array}$ & $\begin{array}{c}5 \\
\text { SS } \\
(\%)\end{array}$ & & \\
\hline $\begin{array}{l}\text { Mengerjakan pekerjaan sesuai dengan } \\
\text { deskripsi pekerjaan }\end{array}$ & 3 & 3 & 39,4 & 45,5 & 9,1 & 45,5 & Setuju \\
\hline $\begin{array}{l}\text { Menyelesaikan tugas dengan benar sesuai } \\
\text { ketentuan }\end{array}$ & 0 & 9,1 & 54,5 & 36,4 & 0 & 54,5 & $\begin{array}{l}\text { Kurang } \\
\text { Setuju }\end{array}$ \\
\hline $\begin{array}{l}\text { Rela mengulang pekerjaan jika dirasa tidak } \\
\text { sesuai dengan standar }\end{array}$ & 0 & 0 & 18,2 & 57,6 & 24,2 & 57,6 & Setuju \\
\hline $\begin{array}{l}\text { Berusaha meningkatkan kompetensi untuk } \\
\text { menyesuaikan dengan kebutuhan pekerjaan }\end{array}$ & 0 & 3 & 27,3 & 54,5 & 15,2 & 54,5 & Setuju \\
\hline $\begin{array}{l}\text { Memanfaatkan pengetahuan teknis untuk } \\
\text { meningkatkan kualitas pekerjaan }\end{array}$ & 0 & 3 & 12,1 & 57,6 & 27,3 & 57,6 & Setuju \\
\hline
\end{tabular}

Sumber: Data diolah (2018)

*Keterangan: STS = Sangat Tidak Setuju, TS = Tidak Setuju, KS = Kurang Setuju, S = Setuju, SS = Sangat Setuju

Tabel 11 menunjukkan modus jawaban karyawan pada setiap pernyataan. Karyawan setuju bahwa mereka sudah mengerjakan pekerjaan sesuai dengan deskripsi yang diberikan, menyelesaikannya dengan benar dan sesuai ketentuan. Karyawan juga bersedia mengulang pekerjaan jika pekerjaan yang sudah dikerjakan dianggap tidak sesuai dengan standar, dan agar tidak selalu mengulang-ulang pekerjaan, karyawan juga setuju untuk terus berusaha meningkatkan kompetensi dan pengetahuan teknis demi meningkatkan kualitas pekerjaan dan mengurangi kesalahan.

\section{Persepsi Karyawan DSITD IPB Terhadap Aspek Waktu}

Waktu merupakan salah satu aspek dari kinerja karyawan. Persepsi karyawan tentang aspek waktu dapat dilihat pada Tabel 12. 
Tabel 12. Persepsi Karyawan DSITD IPB tentang Aspek Waktu

\begin{tabular}{lccccccll}
\hline \multicolumn{1}{c}{ Pernyataan } & 1 & 2 & 3 & 4 & 5 & Modus & Keterangan \\
& STS & TS & KS & S & SS & & \\
& $(\%)$ & $(\%)$ & $(\%)$ & $(\%)$ & $(\%)$ & & \\
\hline Masuk kerja tepat waktu & 3 & 3 & 39,4 & 45,5 & 9,1 & 45,5 & Setuju \\
$\begin{array}{l}\text { Menyelesaikan pekerjaan tepat waktu } \\
\text { Menyelesaikan pekerjaan lebih cepat dari }\end{array}$ & 0 & 9,1 & 54,5 & 36,4 & 0 & 54,5 & $\begin{array}{l}\text { Kurang } \\
\text { Setuju }\end{array}$ \\
$\begin{array}{l}\text { deadline } \\
\begin{array}{l}\text { Belum akan pulang jika pekerjaan belum } \\
\text { terselesaikan }\end{array}\end{array}$ & 0 & 3 & 18,2 & 57,6 & 24,2 & 57,6 & Setuju \\
\hline
\end{tabular}
Sumber: Data diolah (2018)

*Keterangan: STS = Sangat Tidak Setuju, TS = Tidak Setuju, KS = Kurang Setuju, S = Setuju, SS $=$ Sangat Setuju

Tabel 12 menunjukkan modus jawaban karyawan pada setiap pernyataan. Karyawan setuju bahwa mereka masuk kerja tepat pada waktu yang sudah ditentukan. Karyawan kurang setuju terhadap pernyataan bahwa karyawan biasa menyelesaikan pekerjaan tepat pada waktunya karena terkadang karyawan menyelesaikan pekerjaan lebih cepat dari deadline yang ditentukan, sesuai dengan keadaan bahwa sebuah sistem informasi harus sudah selesai sebelum waktu rilis, selesai yang dimaksud adalah sudah memenuhi standar minimal kebutuhan dari pengguna sistem. Karyawan juga setuju jika karyawan belum akan pulang jika pekerjaan belum terselesaikan.

\section{Pengaruh Employee Engagement Terhadap Kinerja Karyawan}

Uji Asumsi Klasik

Uji asumsi yang digunakan di penelitian ini adalah Uji Multikolinearitas, Uji Autokorelasi, Uji Heteroskedastisitas dan Uji Normalitas. Berikut hasil dari uji asumsi klasik tersebut.

1. Uji Normalitas

Hasil analisis grafik normal probability plot pada Gambar 3 menunjukkan bahwa sebaran titik-titik pada gambar mengikuti garis diagonalnya. Maka dapat disimpulkan bahwa model regresi linear berganda antara employee engagement terhadap kinerja karyawan berdistribusi normal.

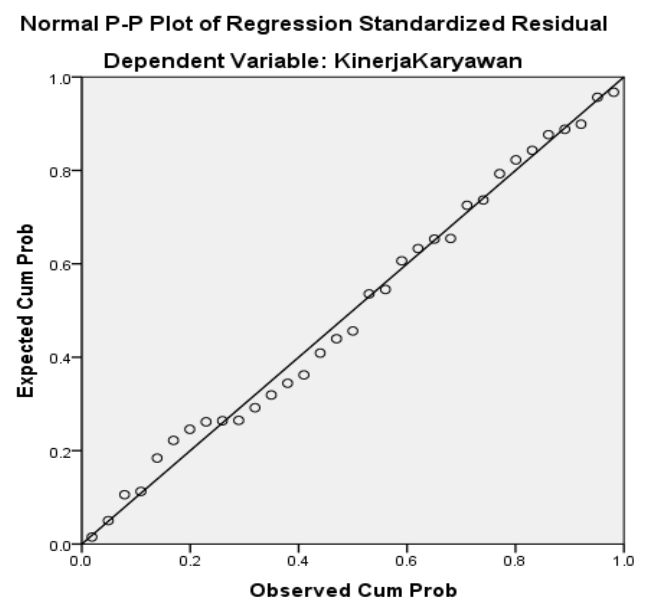

Gambar 3. Hasil Analisis Normal Probability Plot.

2. Uji Heteroskedastisitas

Hasil yang dapat dilihat pada Gambar 4 menunjukkan titik-titik pada gambar tidak membentuk suatu pola tertentu yang teratur. Gambar di atas memperlihatkan bahwa titik-titik menyebar di atas dan di bawah angka 0 pada sumbu Y dengan tidak teratur. Maka dapat disimpulkan bahwa tidak terjadi heteroskedastisitas. 


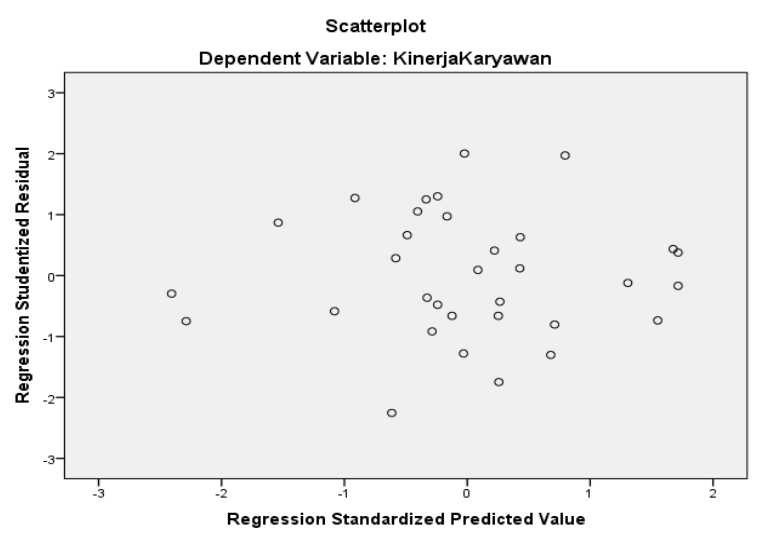

Gambar 4. Hasil Analisis Uji Heteroskedastisitas.

3. Uji Multikolinearitas

Tabel 13. Hasil Uji Multikolinearitas

\begin{tabular}{lllll}
\hline Model & & Absorption & Dedication & Vigor \\
\hline Correlations & Absorption & 1,000 & $-0,321$ & $-0,363$ \\
& Dedication & $-0,321$ & 1,000 & $-0,579$ \\
& Vigor & $-0,363$ & $-0,579$ & 1,000 \\
Covariances & Absorption & 0,031 & $-0,013$ & $-0,014$ \\
& Dedication & $-0,013$ & 0,050 & $-0,028$ \\
& Vigor & $-0,014$ & $-0,028$ & 0,046 \\
\hline
\end{tabular}

Sumber: Data diolah (2018)

Menggunakan besaran koefisien korelasi antar variabel bebas dari output di atas, terlihat koefisien korelasi antar variabel bebas berada pada rentang $(-0,576)-(-0,014)$, jauh di bawah 0.60 , disimpulkan bahwa antar variabel bebas tidak terjadi multikolinearitas.

4. Uji Autokorelasi

Hasil uji autokorelasi dapat dilihat pada Tabel 14.

Tabel 14. Hasil Uji Autokorelasi

\begin{tabular}{cc}
\hline Model & Durbin-Watson \\
\hline 1 & 1,405 \\
\hline
\end{tabular}

Sumber: Data diolah (2018)

Hasil dari uji autokorelasi di atas, ditemukan Durbin-Watson test $=1,961$ dan DW berada diantara -2 dan $2(-2<$ DW < 2) maka dapat disimpulkan bahwa hasil dari uji autokorelasi di atas adalah tidak terjadi autokorelasi.

Uji Regresi Linear Berganda

Variabel dalam penelitian ini adalah employee engagement dan variabel kinerja karyawan. Tabel 15 menunjukkan bahwa tidak terdapat pengaruh secara parsial antara elemen-elemen pada variabel employee engagement terhadap variabel kinerja karyawan.

Tabel 15 Hasil Uji Regresi Linear Berganda

Jurnal Manajemen

dan Organisasi

Vol. 10 No. 2 ,

Agustus 2019,

Hal. 133-146

\begin{tabular}{|c|c|c|c|c|c|}
\hline \multirow{2}{*}{ Model } & \multicolumn{2}{|c|}{ Unstandardized Coefficients } & \multirow{2}{*}{$\frac{\text { Standardized Coefficients }}{\text { Beta }}$} & \multirow[b]{2}{*}{$t$} & \multirow{2}{*}{ Sig. } \\
\hline & $B$ & Std. Error & & & \\
\hline (Constant) & $-0,341$ & 0,540 & & $-0,631$ & 0,533 \\
\hline Vigor & 0,112 & 0,215 & 0,096 & 0,521 & 0,606 \\
\hline Dedication & 0,417 & 0,224 & 0,338 & 1,863 & 0,073 \\
\hline Absorption & 0,520 & 0,177 & 0,465 & 2,929 & 0,007 \\
\hline
\end{tabular}

Sumber: Data diolah (2018)

Tabel 15 menunjukkan nilai korelasi berganda, yaitu korelasi antar dua atau lebih elemen pada variabel independen terhadap variabel dependen. Angka $R$ yang didapat adalah 0,821, artinya korelasi antar elemen vigor, dedication dan absorption terhadap kinerja karyawan sebesar 
82,1 persen, hal ini berarti terjadi hubungan erat antara elemen vigor, dedication dan absorption terhadap kinerja karyawan yang dibuktikan dengan nilai $\mathrm{R}$ yang mendekati 1 .

Tabel 16. Cofariance Regresi Linear Berganda

\begin{tabular}{ccccc}
\hline Model & $R$ & $R$ Square & Adjusted $R$ Square & Std. Error of the Estimate \\
\hline 1 & 0,821 & 0,675 & 0,641 & 0,366 \\
\hline
\end{tabular}

Sumber: Data diolah (2018)

Tabel 16 menunjukkan koefisien determinasi. Nilai R Square sebesar 0,675 berarti sumbangan pengaruh elemen vigor, dedication dan absorption terhadap kinerja karyawan adalah sebesar 67,5 persen. Sedangkan sisanya dipengaruhi oleh variabel lain yang belum masuk dalam model ini. Untuk hasil lengkap regresi linear berganda dari output SPSS dapat dilihat pada Lampiran 3.

\section{Uji Hipotesis}

Tabel 17 memperlihatkan nilai F-hitung yang diperoleh sebesar 20.038 hal itu dapat terlihat dari nilai signifikansi yang lebih kecil dari 0,05 dan df1: $(k-1)=2$ dan df2: $(n-k-1)=29$ (dengan $\mathrm{n}$ sebagai jumlah data dan $\mathrm{k}$ adalah jumlah variabel independen) maka diperoleh F-tabel $(\mathrm{Ft})$ sebesar 3,327, karena nilai F-tabel lebih besar dari F-hitung $(20,038>3,327)$ dan nilai signifikansi pada Uji F kurang dari $0,05(0,000<0,05)$ maka dapat diartikan bahwa vigor, dedication dan absorption secara bersama-sama berpengaruh terhadap kinerja karyawan.

Tabel 17. Hasil Uji Hipotesis

\begin{tabular}{cccccc}
\hline Model & Sum of Squares & df & Mean Square & F & Sig. \\
\hline Regression Residual Total & 8,080 & 3 & 2,693 & 20,038 &, 000 \\
& 3,898 & 29 & 0,134 & & \\
& 11,979 & 32 & & & \\
\hline
\end{tabular}

Sumber: Data diolah (2018)

Tabel 18. Coefficient Corelation

\begin{tabular}{|c|c|c|c|c|c|}
\hline \multirow{2}{*}{ Model } & \multicolumn{2}{|c|}{ Unstandardized Coefficients } & \multirow{2}{*}{$\begin{array}{c}\begin{array}{c}\text { Standardized } \\
\text { Coefficients }\end{array} \\
\text { Beta }\end{array}$} & \multirow{2}{*}{$t$} & \multirow{2}{*}{ Sig. } \\
\hline & $B$ & Std. Error & & & \\
\hline (Constant) & $-0,341$ & 0,540 & & $-0,631$ & 0,533 \\
\hline Vigor & 0,112 & 0,215 & 0,096 & 0,521 & 0,606 \\
\hline Dedication & 0,417 & 0,224 & 0,338 & 1,863 & 0,073 \\
\hline Absorption & 0,520 & 0,177 & 0,465 & 2,929 & 0,007 \\
\hline
\end{tabular}

Sumber: Data diolah (2018)

Tabel 18 memperlihatkan masing-masing nilai T-hitung dari setiap variabel dan bandingkan dengan nilai T-tabel. Nilai T-tabel dicari dengan rumus n-k-1 maka 33-3-1=29 Dimana kriteria dari hipotesis adalah sebagai berikut:

T-hitung $<$ T-tabel atau sig. $>\alpha=\mathrm{H}_{0}$ diterima, $\mathrm{H}_{1}$ ditolak

T-hitung $>\mathrm{T}$-tabel atau sig. $<\alpha=\mathrm{H}_{0}$ ditolak, $\mathrm{H}_{1}$ diterima

Berdasarakan kriteria diatas maka hasil interpretasi bagi tiap-tiap indikator employee engagement dapat dilihat sebagai berikut:

1. Vigor

Hasil hipotesis untuk variabel vigor adalah:

$\mathrm{H}_{0}$ : Vigor tidak berpengaruh positif dan signifikan terhadap kinerja karyawan.

$\mathrm{H}_{1}$ : Vigor berpengaruh positif dan signifikan terhadap kinerja karyawan.

Hasil dari Uji T pada tabel menunjukan bahwa nilai T-hitung untuk variabel Vigor sebesar 0,521. Nilai T-hitung lebih kecil dari T-tabel $(0,521<2,045)$ maka $\mathrm{H}_{0}$ diterima dan $\mathrm{H} 1$ ditolak. Dapat disimpulkan bahwa Vigor tidak memiliki pengaruh positif dan signifikan terhadap kinerja karyawan.

2. Dedication

Hasil hipotesis untuk variabel dedication adalah:

$\mathrm{H}_{0}$ : Dedication tidak berpengaruh positif dan signifikan terhadap kinerja karyawan 
$\mathrm{H}_{1}$ : Dedication berpengaruh positif dan signifikan terhadap kinerja karyawan..

Hasil dari Uji $\mathrm{T}$ pada tabel menunjukan bahwa nilai T-hitung untuk variabel Dedication sebesar 1,759. Nilai T-hitung lebih kecil dari T-tabel $(1,759<2,045)$ maka $\mathrm{H}_{0}$ diterima dan $\mathrm{H}_{1}$ ditolak. Dapat disimpulkan bahwa dedication tidak memiliki pengaruh positif dan signifikan terhadap kinerja karyawan.

3. Absorption

Hasil hipotesis untuk variabel absorption adalah:

$\mathrm{H}_{0}$ : Absorption tidak berpengaruh positif dan signifikan terhadap kinerja karyawan.

$\mathrm{H}_{1}$ : Absorption berpengaruh positif dan signifikan terhadap kinerja karyawan.

Hasil dari Uji T pada tabel menunjukan bahwa nilai T-hitung untuk variabel absoprtion sebesar 2,929. Nilai T-hitung lebih besar dari T-tabel $(2,929>2,045)$ maka $\mathrm{H}_{0}$ ditolak dan $\mathrm{H}_{1}$ diterima. Dapat disimpulkan bahwa absorption memiliki pengaruh positif dan signifikan terhadap kinerja karyawan.

\section{Implikasi Manajerial}

Employee engagement seorang karyawan dapat menentukan usaha karyawan dalam pekerjaan yang dilakukannya sehari-hari, mempengaruhi loyalitasnya, juga keputusan karyawan untuk tetap bertahan atau keluar dari tempat kerjanya. Implikasi Manajerial dari penelitian ini dapat dilihat pada Tabel 19.

Tabel 19. Implikasi Manajerial

\begin{tabular}{|c|c|}
\hline Elemen/Aspek & Implikasi Manajerial \\
\hline Vigor & $\begin{array}{l}\text { Adanya pertimbangan untuk memberikan penyuluhan kesehatan dan keselamatan kerja } \\
\text { yang khusus ditujukan untuk para pegawai bidang IT, selanjutnya arahan untuk } \\
\text { melakukan senam ringan dalam interval waktu tertentu agar tidak terjadi kejenuhan } \\
\text { pada tubuh yang sudah bekerja dalam keadaan yang sama dalam waktu yang lama. }\end{array}$ \\
\hline Dedication & $\begin{array}{l}\text { Perlu ada perbaikan dalam mekanisme tahapan perekrutan dan penugasan karyawan, } \\
\text { karena masih ditemukan sebagian kecil karyawan merasa tidak antusias dengan apa } \\
\text { yang dikerjakan. Hal tersebut diduga terjadi karena ketidaksesuaian kompetensi } \\
\text { dan/atau keilmuan yang karyawan miliki dengan penempatan bidang kerjanya. }\end{array}$ \\
\hline Kualitas & $\begin{array}{l}\text { Karyawan diberikan kesempatan untuk mengikuti pelatihan yang dapat meningkatkan } \\
\text { kompetensi dan kemampuan teknisnya, karyawan yang masih baru dikolaborasikan } \\
\text { dengan karyawan yang berpengalaman dalam penugasan, dan memotivasi para } \\
\text { karyawan untuk terus berinovasi. }\end{array}$ \\
\hline Waktu & $\begin{array}{l}\text { Diberlakukan reward and punishment untuk meningkatkan kedisiplinan dalam } \\
\text { masalah waktu, perlu adanya manajemen proyek yang baik dan perlu ditentukan } \\
\text { prioritas dan deadline pekerjaan yang jelas. }\end{array}$ \\
\hline
\end{tabular}

Sumber: Data diolah (2018)

\section{KESIMPULAN}

Berdasarkan hasil penelitian yang telah dilakukan, maka dapat ditarik kesimpulan sekaligus menjawab perumusan masalah dari penelitian. Pertama employee engagement di DSITD IPB berada pada kategori baik, elemen vigor, dedication dan absorption dari variabel employee engagement semua berada pada kategori baik. Nilai tertinggi diperoleh oleh elemen dedication sedangkan yang paling rendah dari elemen vigor. Kedua kinerja karyawan di DSITD IPB berada pada kategori baik, seluruh aspek dari variabel kinerja karyawan ada pada kategori baik. Ketiga elemen-elemen employee engagement seperti vigor, dedication dan absorption secara bersamasama mempengaruhi kinerja karyawan DSITD IPB sebesar 67,5 persen.

Berdasarkan hasil penelitian maka peneliti bermaksud untuk memberikan saran, pertama DSITD IPB tetap mempertahankan employee engagement karyawan yang sudah ada pada kategori baik, namun elemen vigor masih perlu diberikan perhatian. Elemen vigor masih memerlukan peningkatan, cara yang ditempuh misalnya menata kembali desain kantor agar karyawan dapat merasakan lingkungan kerja yang kondusif dan nyaman sehingga tidak menimbulkan hal-hal yang nantinya dapat mengurangi tingkat kebugaran fisik para karyawan. 
penelitian ini. Faktor-faktor yang dapat meningkatkan kinerja karyawan tersebut misalnya kompensasi, beban kerja atau quality of work life.

\section{DAFTAR PUSTAKA}

[BKN] Badan Kepegawaian Nasional. (2011). Pedoman Penyusunan dan Penilaian Sasaran Kinerja Pegawai di Lingkungan Badan Kepegawaian Negara. Jakarta: Badan Kepegawaian Nasional.

Fisher, C. D, Schoenfeldt, L. F., \& Shaw, J. B. (2006). Human Resource Management. $\left(6^{\text {th }}\right.$ edition). Boston: Houghton Mifflin Company.

Kahn, W. A. (1990). Psychological conditions of personal engagement and disengagement at work. Academy of Management Journal, 33, 692-724.

Markos, S., \& Sridevi, M. S. (2010). Employee Engagement: The Key to Improving Performance. International Journal of Business and Management. 5(12), 89-96. Diakses pada: http://citeseerx.ist.psu.edu/viewdoc/download?doi=10.1.1.466.1591\&rep=rep1\&type=pd.

Shcaufeli, W., \& Bakker, A. (2004). Utrecth Work Engagement Scale Preminaly Manual, Utrecth/Valencia [ES]: Occupational Health Psychology Unit Utrecth University.

Surur, N. (2018). Upaya TPK Koja Bentuk Employee Engagement [Wawancara] (2 Januari 2018).

Sutiyadi. (2017). Analisis Pengaruh Sistem Informasi Manajemen Berbasis Komputer, Pelatihan dan Disiplin Kerja Terhadap Kinerja Pegawai Kantor Pemerintahan Provinsi DKI Jakarta. Jurnal Riset Manajemen dan Bisnis. 2, 53-62.

Suwatno, \& Priansa, D. J. (2011). Manajemen SDM dalam Organisasi Publik dan Bisnis. Bandung: Alfabeta. 